\title{
El autor en vuelo o la escena icaria-dedálica: la aviación pionera y la modernidad literaria (Kafka, Hesse y D’Annunzio)
}

\author{
The author in flight or the icaria-dedálica scene: pioneer aviation and literary \\ modernity (Kafka, Hesse and D'Annunzio)
}

Felix Philipp Ingold

xpd@bluewin.ch

Prof. Em. de la Universidad de St Gallen, Suiza

Cita sugerida: Ingold, F. P. (2021). El autor en vuelo o la escena icaria-dedálica: la aviación pionera y la modernidad literaria (Kafka, Hesse y D’Annunzio). Orbis Tertius, 26(33), e195. https://doi.org/10.24215/18517811e195
Resumen: Este ensayo es una traducción de un fragmento de la primera de tres partes de Der Autor am Werk, de Felix Philipp Ingold, publicado en 1992 por la editorial Hanser, München. El autor fue sumamente generoso en ceder el fragmento de su texto para la traducción al castellano, y especialmente para este dosier. Las cursivas que aparecen en el presente texto son del autor. Las notas corresponden al texto original; algunas de ellas fueron abreviadas, así como el párrafo sobre el despegue y la caída como escenas icarias. El texto original presenta una considerable cantidad de imágenes que aquí no pueden ser reproducidas, sin embargo, algunas pocas fueron reemplazadas por fuentes accesibles en internet y sus leyendas remiten a los comentarios originales del autor.

Palabras clave: Felix Ingold, Literatura y aviación, Vuelo humano, Modernidad técnica, Modernidad literaria.

Abstract: This essay is a translation of an excerpt from the first of three parts of Felix Philipp Ingold's Der Autor am Werk, published in 1992 by Hanser, München. The author was extremely generous in giving the fragment of his text for translation, and especially for this dossier. The italics that appear in this text are the author. The notes correspond to the original text; some of them were abbreviated, as well as the paragraph on takeoff and fall as Icarian scenes. The original text presents a considerable number of images that cannot be reproduced here, however, a few were replaced by sources accessible on the Internet and their captions refer to the original comments of the author.

Keywords: Felix Ingold, Literature and aviation, Human flight, Technical modernity, Literary modernity.

Según ${ }^{*}$ la aviática ${ }^{1}$-que en aquel momento aún era denominada 'arte de volar' (Fliegekunst) ${ }^{2}$ - iba abandonando, por un lado, la ya centenaria imitación del vuelo del pájaro y, por otro, dejando atrás la (muy exitosa) aviación aerostática contemporánea en favor de un procedimiento de vuelo completamente 
novedoso, en gran medida incierto, no ensayado y apenas legítimo en términos teóricos, esta realizó, al mismo tiempo que la física relativista y el psicoanálisis, un giro paradigmático que no solamente contradijo cualquier tradición, sino también cualquier comparación natural -y por tanto cualquier probabilidad-, y que llevó, sin embargo, a corto plazo, al éxito. No el globo, ni tampoco la aeronave, sino solamente el avión motorizado, devenido máquina, provisto de hélices, de una estructura de soporte rígida y un sistema de mano integrada -que además tenía que ser "más pesado que el aire"-, podía ser la realización del sueño icario y a la vez la solución de un problema técnico milenario: como un avión que se puede valer "por sí solo", creado para el ascenso autoimpulsado, hacia los "celestes silencios", "para en los perfiles luminosos / jugar a favorito de los vientos, / como un útil que sabe su eficacia, / firme balanceándose y seguro" (Rilke, 1983, p. 46; Rilke, 1955, p. $\left.745^{3}\right) .^{4}$

En un artículo publicado en 1919, y frente a los resultados de la Revolución de Octubre, Kazimir Malévich dio fe de manera muy ilustrativa de que las verdaderas soluciones -así sean en el terreno técnico, artístico o político- solamente se logran si "los hombros alados" del avión son "liberados" de la "carga" de "los abuelos y las abuelas": "¿Puede el piloto a esta altura de nuestros nuevos conocimientos acaso encontrar alguna utilidad en Rubens, en la Gran Pirámide de Guiza o en la descarada Venus [de Milo]?” (Malévich, 1977, pp. 64-65). La tradición, según Malévich, debía pasar al olvido, para que "los renovadores de la época moderna" pudiesen iniciar sin mayor obstáculo su "carrera creadora" y concebir, mediante un "veloz salto hacia adelante", formas nuevas, que no mantuviesen más ningún tipo de vínculo con los viejos tiempos.

"El avión nos muestra", así anotó Le Corbusier algo más tarde volviendo la mirada hacia los inicios del vuelo motorizado,

que un problema bien planteado siempre tiene solución. Querer volar como un pájaro significó plantear el problema de manera equivocada, así como el murciélago de Ader nunca pudo desprenderse del suelo. Inventar una máquina de volar sin todos esos recuerdos atados a lo que aún estaba tan alejado de la mecánica pura, es decir, buscar una estructura de soporte y una fuerza impulsora, significa plantear el problema de la manera correcta: en menos de diez años, todo el mundo iba a poder volar. (Le Corbusier, 1926, p. 91). 
FIG.1

Vuelo motorizado versus vuelo de pájaro: Glenn Curtis en su biplano, cuya estructura poco tenía que ver con los diseños ornitomorfos

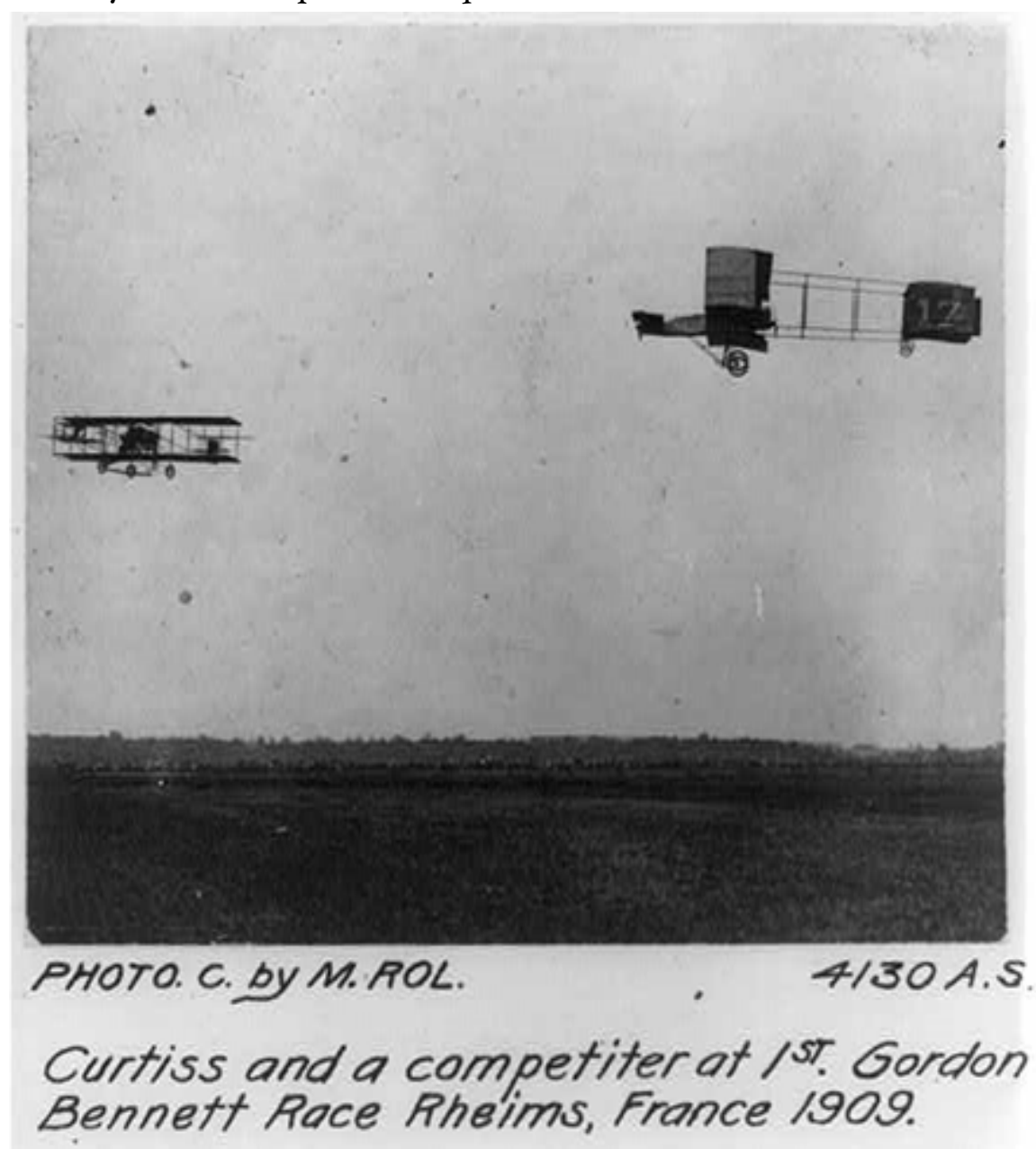

Fuente: https://commons.wikimedia.org/w/index.php?curid=2984543

Y en otro punto del texto dice:

¡Se logró! El hombre (más pesado que el aire y en un aparato más pesado que el aire) ha alzado vuelo. - Esto ocurrió antes de la Gran Guerra. - En aquel momento, ¡no existía ninguna meta precisa! No se intuía aún que algún día podría nacer de esto algún tipo de idea, ni que esa idea podría convertirse en el símbolo de la nueva época. Consideremos este hecho tan esencial como fundamental. Los grandes inventos ocurren de manera desinteresada, pues sus consecuencias son impredecibles. El inventor, el creador, ambos persiguen una quimera mental, de manera que en algún cruce de caminos probablemente den con ella de modo imprevisto, aunque sus ojos aún tendrán que verla y sus manos tocarla. Repito una y otra vez: debemos estar alertas, de por vida y a cada instante, para poder retener el milagro en las cosas (Le Corbusier, 1935, p. 8).

El "milagro" del vuelo motorizado consistía en que este le permitía al hombre invertir de algún modo el vuelo en planeo o el vuelo estacionario, y así, en vez de estar solamente expuesto a la interacción entre la fuerza ascensional y la gravedad, moverse a una cierta velocidad y en cualquier dirección por el aire, de manera horizontal o incluso ascendente. Como afirmó Herbert Silberer en un informe de situación respecto de la seguridad de vuelo en 1909:

El hombre no es capaz de proveer la propulsión con su propia fuerza muscular; de ahí que necesita la asistencia de un pequeño, pero potente motor. También se está logrando modificar el manejo del volante de manera más o menos satisfactoria; se evita que el piloto tenga que realizar los movimientos corporales para distribuir el peso (tan imprescindibles en el manejo 
del planeador), poniendo a su disposición unas palancas que están al servicio de diferentes dispositivos de dirección. Pero todo esto al fin y al cabo no es otra cosa que la exteriorización de las capacidades personales, una prolongación de los nervios, músculos, tendones y extremidades del conductor. Probablemente este se sienta más unido a su máquina voladora que el jinete a su caballo; junto con su máquina, conforma un único ser. (Silberer, 1909, p. 289)

Silberer -que pertenecía a los comentaristas de los acontecimientos de la aviación europea más reconocidos, a nivel internacional, de su tiempo- además insiste en el parecido entre el "aeroplanista" y los "hombres míticos con ansia de volar"; subraya que "la máquina voladora dinámica que conduce la fuerza latiente de su corazón de motor palpitante a través de músculos de acero y hacia órganos con forma de alas para revolotear por el aire" se estaría acercando de manera ideal al modelo del "hombre volador" dedálicoicárico. Además, dio un ejemplo muy locuaz del esfuerzo, tan frecuente en aquel entonces, de aprehender a la máquina como un órgano adicional del hombre, y no al hombre como una pieza de repuesto de la máquina. También ejemplifica que la tan repentina racionalización y des-mitologización del sueño de volar tampoco fue realizada, o al menos no enseguida, de manera consciente por la opinión pública ilustrada, lo que permite hacerse una idea de cuán difícil habrá sido para un público más amplio tener que pagar con la respectiva pérdida de un sueño lo que la aviación hacia 'ganar en términos de realidad' (Wirklichkeitsgewinn) ${ }^{8}$ (p. 290).

Existen una cantidad innumerable de documentos textuales y visuales de la época pionera de la aviación motorizada sobre los que se debería aún comprobar el hecho de que la tan recurrente referencia al mito de Dédalo e Ícaro, hecho ahora sí realidad y por tanto prácticamente superado, no expresaba otra cosa que la inquietud no asumida de que si después de la "conquista del cielo", el hombre realmente podría ser reconocido como Maestro y Señor de los aparatos que él mismo creó, o si su futura función no estaría más bien limitada a ser "rueda y tornillo" (Lenin, 1905) en una civilización completamente mecanizada. Como bien sabemos, esta pregunta sigue vigente hasta el día de hoy; y por su parte, Franz Kafka se le ha acercado, aunque sin pretender responderla, en un temprano texto periodístico. ${ }^{9}$ Basándose en observaciones personales, y sin ningún tipo de decorado metafórico, la abordó describiendo cómo los intentos de vuelo contemporáneos se presentaban a su mirada, es decir, a su percepción sensorial, lo que le permitió ilustrar de manera neutral la entre heroica y desamparada conjunción de hombre y máquina en su imprevisible fatalidad:

... Blériot ya se encuentra en el aire, su torso recto haciéndose visible por encima de las alas, las piernas hundidas, formando parte de la maquinaria. El sol se ha inclinado y, atravesando los baldaquines de las tribunas, ilumina las alas flotantes. Todo el mundo está completamente entregado y mira hacia arriba para verlo, no hay corazón que le reserve un lugar a otro. Da una pequeña ronda y a continuación aparece casi verticalmente sobre nosotros. Todo el mundo estira el cuello, para ver cómo el monoplano tambalea, es agarrado por Blériot y hasta llevado a mayor altura. ¿Qué sucede? Allá arriba, a veinte metros de la tierra, un hombre se halla atrapado en un armazón de madera y se defiende de un peligro invisible que él mismo asumió de manera voluntaria. Nosotros mientras tanto nos encontramos abajo, retrocediendo e insustanciales, y observamos a ese hombre (Kafka, 1977, p. 21).

Kafka, que en otoño de 1909 había presenciado el meeting aéreo de Brescia, no quedó impresionado ni por la valentía, ni por la destreza del piloto, sino por todo lo contrario: la mediocridad del evento. Los héroes del día, que comúnmente se veían acompañados por sus esposas y sus hijos, resultaban ser personas corrientes; volar para ellos no era más que un trabajo para ganarse la vida, que perseguían con tanta perseverancia como sobriedad, sin poder a la vez evitar que su labor fuera titánicamente enaltecida por las necesidades sensacionalistas y de identificación del público.

Ya instalado en su asiento, Blériot pone la mano en alguna de las palancas, pero aún permite que los mecánicos hagan su trabajo, como si se tratara de niños demasiado ajetreados. Voltea la mirada hacia nosotros, para enseguida mirar hacia otro lado, pero a la vez conteniendo la mirada. Ahora volará, nada más natural. Esta sensación de lo natural mezclada con la sensación simultánea y general de lo extraordinario, que no se desprende de él, le da esa postura. (p. 17). 
Y hasta Rougier, que a continuación alcanzaría la máxima altura de vuelo y se convertiría en el favorito del público, "está sentado frente a las palancas como un Señor en su escritorio, al cual se puede acceder a sus espaldas, subiendo una escalerita” (p. 24).

El reportaje de Kafka se diferencia de otros textos periodísticos y literarios de la época pionera de la aviación por su casi visionaria objetividad, que no deja que se asome ni lo demoníaco ni el pathos, pero a la vez logra hacer creíble la dimensión ambivalente del instante con todas sus implicaciones civilizatorias. Muy al contrario de lo que ocurre en este texto, era muy común glorificar a los aviadores, tratarlos, sin crítica alguna, como heraldos de una inminente era mecánica de la cual se esperaba más la realización de sueños antiguos que aquella de ideas nuevas. Con lo que parecería explicarse el hecho tan extraño de que el vuelo motorizado, habiendo sido desacreditada de una vez por todas la naturaleza como modelo de la técnica, seguía siendo vinculado al vuelo del pájaro y al imaginario mitológico que se derivaba de aquel. En este contexto llama además la atención que entre las comparaciones más pertinentes que se hacían del mito del vuelo y la realidad de este, el habitual favoritismo de Ícaro frente a Dédalo se mantiene por completo, aunque el tipo de piloto dominante del momento -frecuentemente inventor, diseñador y piloto en una persona- era mucho más cercano al mechanopoiós dedálico que al aventurero icárico.

FIG. 2

Vuelo humano versus vuelo motorizado: el sastre franco-austriaco Franz Reichelt y su 'paracaídas'10



Fuente: https://de.wikipedia.org/wiki/Franz_Reichelt\#/media/Datei:Flying_tailor.png

Son muy esclarecedores al respecto dos informes de experiencia de Hermann Hesse, autor que en Europa se contaba entre los pocos literatos que habían dejado por escrito sus experiencias de vuelo antes de la Primera Guerra Mundial. En el verano de 1911, Hesse había participado de un paseo aéreo ("Spazierfahrt in der Luft”), como pasajero del zepelín Schwaben, pero no había sentido "ni excitación ni miedo", porque la "cabina 
tan elegante" del zepelín se asemejaba más bien a un "confortable vagón comedor o vagón panorámico" y menos al "juguete" peligroso al que tanto se parecían los "andamiajes vestidos de lienzo" de los aparatos de vuelo del momento. Junto con Oskar Bider, Hesse realizó en marzo de 1913 un vuelo panorámico en un monoplano sobre Berna, y solamente en esa ocasión se percató de que mientras el aerostato únicamente ampliaba el espacio de experiencia del pasajero ferroviario, "el avión que asciende de manera vertical" conllevaba una experiencia sensorial completamente nueva:

No fueron las fuerzas del caballo ni tampoco las calculaciones de las ciencias técnicas las que de golpe nos levantaron a mí, al avión, a Blériot y a Latham. Fue aquella nostalgia enorme, ya tan antigua, esa terquedad nacida de la impotencia, el legado titánico. Él nos ha enseñado a volar. Sin embargo, con el vuelo no se cumple ningún sueño, el arco es tensado simplemente con más fuerza y más ferocidad, los círculos del deseo se han expandido, el corazón arde de manera más obstinada. [...] ... me hallo sentado como un muchacho, poseído por la experiencia; la razón, la dejé en casa. Arrojo, interrumpido por un dulce temblor ansioso, mi mirada y mi respiración hacia el mundo, como cantos y suspiros, ya sin aliento floto por los espacios, arrastrado por una música tremenda; soy totalmente niño, totalmente muchacho, totalmente aventurero, y a grandes sorbos bebo así el vino embriagador del desprendimiento, de la indiferencia, del desprecio frente a todo lo caduco y de la excitación animal; soy dragón y nube, Prometeo e Ícaro... (Hesse, 1976, p. 130).

En medio de la sensación extática del "desprendimiento", el poeta se encuentra con el piloto; pues ambos, según Hesse, son "sin duda verdaderos aventureros"; "La confirmación de que esto era así fue para mí la noticia de la muerte de Latham, a quien había visto volar sobre Frankfurt, había caído al Canal y que acabó como cazador en los Trópicos" (pp. 130-139). ${ }^{11}$

El hecho de que Ícaro se haya convertido justamente (y exclusivamente) en la figura de referencia simbólica del hombre aviático moderno ("symbolische Referenzfigur des modernen Aviatikers"), y que en esta función fuese apropiado de las formas más diversas tanto por la producción kitsch literaria y plástica como por la literatura más elevada y la vanguardia estética, parecería tener primordialmente dos razones contradictorias entre sí. Por un lado, la altísima cuota de catástrofes y accidentes durante los años fundacionales de la aviación aerodinámica era motivo suficiente para pensar en el destino de Ícaro; ${ }^{12}$ por otro, el interés del público aún en los tiempos de los mega-eventos de la aviación -de los cuales formaban parte el cruce del Canal de la Mancha por Blériot, Lambert volando alrededor de la torre Eiffel y los vuelos récord de Farman- se dirigía ante todo a la fase de despegue, que fue considerada especialmente riesgosa y por tanto solía ser preparada por los pilotos con una laboriosidad altamente ritualizada, pero cuyo atractivo en el fondo consistía en el hecho de que el hombre por primera vez lograba observarse a sí mismo en el acto autoimpulsado y jamás previsto por la naturaleza de superar la fuerza de gravedad terrestre. 
FIG. 3

Una ejemplar catástrofe icaria en la era de la aviación motorizada temprana: Hubert Latham intenta cruzar dos veces el Canal de la Mancha en $1909^{13}$

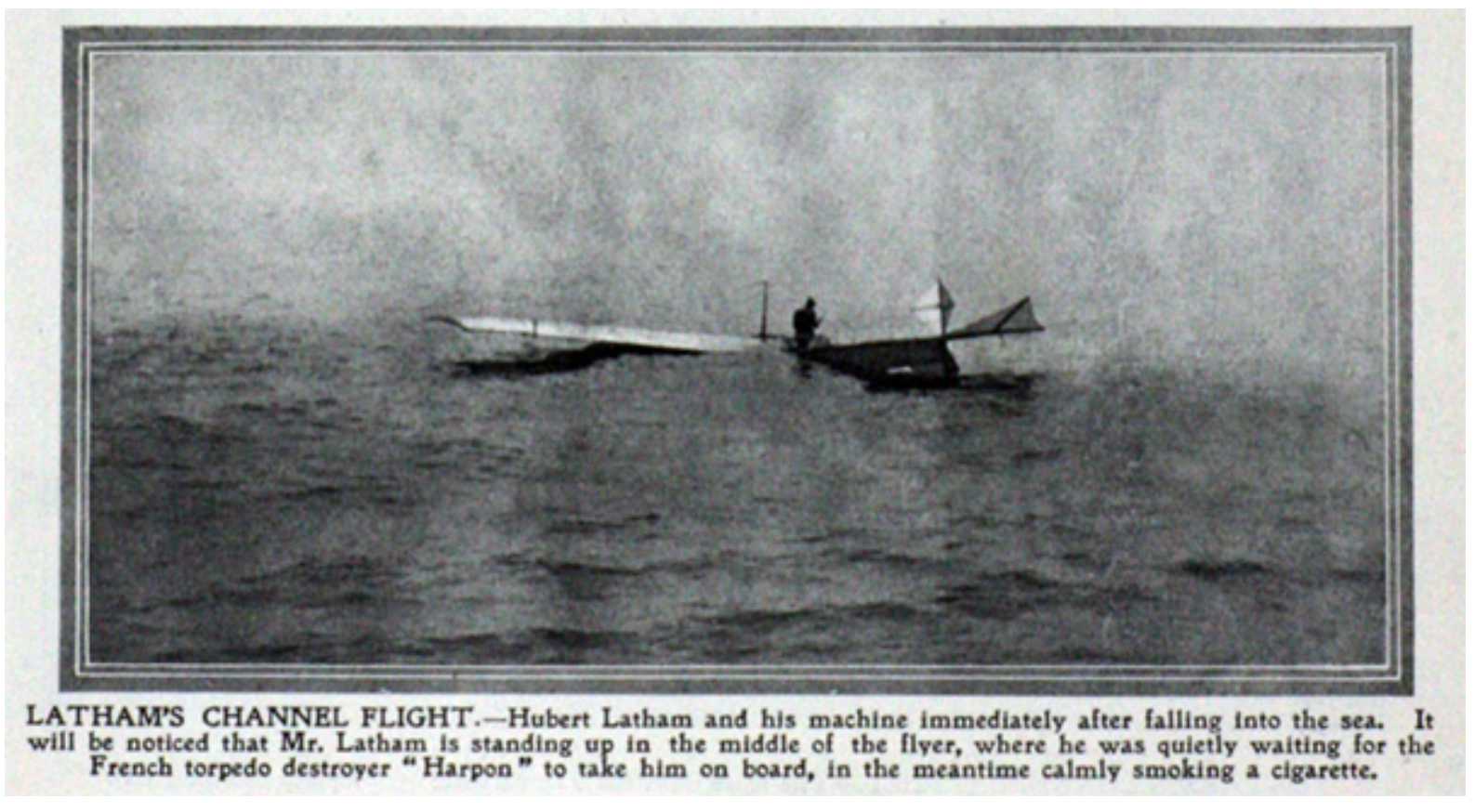

Fuente: https://www.gracesguide.co.uk/File:Im1909FL-Latham10.jpg

La tenacidad con la cual todo se estuvo encaminando para llegar a este punto, la facilidad con la que los aviones lo vivían, fue ilustrada por Kafka de manera muy memorable; y en su informe sobre Brescia dice al respecto:

Un trabajador agarra una de las aspas de la hélice, para ponerla en movimiento, tira de ella; se produce una sacudida, y se percibe algo parecido a la respiración de un hombre robusto al dormir; pero la hélice no se mueve más. Otro intento, diez intentos, algunas veces la hélice se detiene enseguida, en otras se presta para un par de rotaciones. Tiene que ver con el motor. Otros trabajadores retoman la labor, los espectadores comienzan a aburrirse más que los involucrados. De todas partes se le echa aceite al motor; algunas tuercas ocultas son aflojadas y reajustadas; un hombre corre hacia el hangar y vuelve con una pieza de repuesto; de nuevo no sirve; regresa y, en cuclillas sobre el suelo del hangar, teniéndola entre las piernas, la trabaja con un martillo. Blériot toma el puesto de un mecánico, y el mecánico el de Leblanc. Pronto un hombre tira de la hélice, al rato este otro. Pero el motor no tiene piedad, como a un alumno al que siempre se le ayuda, y la clase entera insiste, no, no lo sabe, y otra vez se queda trabado, siempre en el mismo lugar, fracasando. Durante un buen rato, Blériot no se mueve de su asiento, en silencio; sus seis ayudantes lo rodean, ya sin moverse, todos parecen estar soñando [...]. Y otra vez se hace girar la hélice, quizás con más destreza que antes, o quizás no; el motor arranca con mucho ruido, como si fuera otro; cuatro hombres sostienen el aparato por la cola, y en medio de la calma chicha alrededor la corriente de aire causada por la hélice vibrante atraviesa los uniformes de trabajo de estos hombres. No se oye ni una palabra, solamente el ruido de la hélice parece estar dando comandos. Ocho manos despiden al aparato que durante un largo tiempo corre sobre los terrones como alguien torpe sobre unas baldosas de parqué (Kafka, 1977, pp. 17-19).

El realismo sensorial de Kafka, que vuelve palpable el atasco del motor y la impaciencia del piloto incluso en el ritmo tantas veces interrumpido de sus oraciones, contrasta de manera bastante reveladora con un boceto beletrístico de Gabriele D’Annunzio redactado en el mismo tiempo, y que tematiza el accidente letal de un aviador amateur. Se sobreentiende que, en este boceto que versa sobre la apoteosis de un superhombre nietzscheano, el nuevo Ícaro no es presentado con vestimenta mecánica, sino dotado de un nimbo de héroe caído y alabado mediante una retórica de lo más elevada:

Cuando los escombros fueron sacados, los alambres desenredados, los pedazos de lienzo recogidos, salió a la vista el cuerpo inanimado del héroe. La parte trasera de la cabeza estaba adherida a la carcasa del motor de manera tal, que los siete cilindros 
con sus aletas refrigerantes formaban una especie de aureola escalofriante alrededor de su cara. Los ojos, de un marrón claro, estaban rígidamente abiertos, la boca se veía calmada e intrépida, en la barba rubia y suave brillaban los dientes, blancos y puros. La gran vena de la sien había sido cortada en dos por un alambre de tensión roto, de manera lisa, como por un cuchillo de afeitar. De la herida brotaba un arroyo rojo que se extendía por la oreja, el cuello, el hombro y el puño entrecerrado. Un médico, inclinado sobre su pecho para auscultar el corazón que hacía rato no latía más, sintió en su mejilla el fresco vigor de un pétalo de rosa (citado en Ingold, 1978, p. 46). ${ }^{14}$

Desde entonces, el despegue, la caída -las dos escenas centrales del vuelo icario- se desenvuelven en una continuada y aun así nunca idéntica reiteración ante los ojos de todos nosotros, como un paradigma por excelencia de la existencia humana. "El hombre, cuya obra fue crear la máquina de volar y [poder] volar con ella, vio", según Thornton Wilder, “cómo él mismo se movía, hallándose en su propia creación...” (Wilder, 1985, p. 35). Que D’Annunzio, un representante del fin de siécle literario orientado de modo ecléctico hacia el pasado, reconociera en el estado de la aviación actual los aspectos ante todo heroicos y trágicos, mientras Kafka, que, como "hijo eterno", durante toda su vida se esforzó por desprenderse de la fuerza de gravedad del legado paterno, pusiera toda su atención en el momento voluntario y proyectivo del despegue, es ciertamente de una importancia sintomática. Y así vuelve otra vez la pregunta por la escena, primaria, de instrucción icario-dedálica y su dialéctica de la creatividad artística.

\section{ReFERENCIAS}

Duhem, J. (1943). Histoire des idées aéronautiques avant Montgolfier. Paris: Fernand Sorlot.

Hesse, H. (1911). Spazierfahrt in der Luft. En Die Kunst des Müßiggangs (Kurze Prosa aus dem Nachlass). Frankfurt a/M.: Suhrkamp.

Ingold, F. P. (1978). Literatur und Aviatik. Europäische Flugdichtung 1909 bis 1927. Stuttgart: Birkhäuser Verlag. Kafka, F. (1977 [1909]). Die Aeroplane in Brescia. Frankfurt a/M.: Fischer.

Le Corbusier (1935). Aircraft. London: Studio.

Le Corbusier (1926). Kommende Baukunst. Stuttgart: Deutsche Verlagsanstalt.

Lenin, W.I. (13 de noviembre de 1905). La organización del partido y la literatura del partido. Nowaja Shisn, 12.

Malévich, K. (1977 [1919]). Sur le musée. En Le miroir suprématiste. Lausanne: L’Age d'Homme.

Reay, D. (1977). The History of Man-Powered Flight. Oxford: Pergamon.

Rilke, R.M. (1983 [1923]). Sonetos a Orfeo (Carlos Barral, Trad.). Barcelona: Lumen.

Rilke, R. M. (1955). Sonette an Orpheus. Erster Teil. Sämtliche Werke. Tomo I. Frankfurt a/M: Insel.

Silberer, H. (1909). Das Fliegen. Wiener Luftschiffer-Zeitung, 17, 289-291.

Wilder, Th. (1947). Einführung. En Gertrude Stein. Was sind Meisterwerke (pp. 7-46). Zürich: Arche.

\section{Notas}

* La traductora (R.B.) le agradece a Guillermo Andrés Escobar Barrios (Universidad del Norte, Barranquilla) su perspicaz lectura, sus excelentes comentarios y sugerencias en lo relativo a esta traducción.

1 Nota de traducción: El término "aviática” es poco común, como también lo es en alemán. Ingold lo introdujo en el discurso de las poéticas de la aviación. Hoy día, circula aún en ciertos círculos militares.

2 Nota de traducción: Aunque suene un tanto artificioso, "arte de volar" parecería acercarse al sentido que marcó la historia temprana de la aviación. La palabra Fliegekunst, un sustantivo compuesto ("fliegen” = volar; "Kunst" = arte), aparece en el título de la obra de Otto Lilienthal, Der Vogelflug als Grundlage der Fliegekunst (1889); y es traducido como "aviación”. Esta palabra sin embargo se diferencia mucho menos de "aviática", que Fliegekunst de Aviatik.

3 Nota de traducción: Se trata del soneto XXIII de Sonette an Orpheus (redactados en 1922, publicados en 1923). El original reza (los elementos citados en castellano aparecen en cursiva): "O erst dann, wenn der Flug/nicht mehr um seinetwillen/wird in die Himmelstillen/steigen, sich selber genug,//um in lichten Profilen,//als das Gerät, das gelang,/ 
Liebling der Winde zu spielen,/sicher schwenkend und schlank, -//erst wenn ein reines Wohin/wachsender Apparate/ Knabenstolz überwiegt,//wird, überstürzt von Gewinn,/jener den Fernen Genahte/sein, was er einsam erfliegt".

4 Según Duhem puede hablarse del vuelo autodinámico (más pesado que el aire) si el hombre es capaz de "subir voluntariamente en vertical, moverse en cualquier dirección y pararse en cualquier punto, para después descender -sea de manera horizontal, o vertical- con total seguridad" (1943, p. 9).

5 Traducción R.B.

6 Nota de traducción: en alemán dice "Areoplanist”. Es infrecuente, como también en castellano.

7 Nota de traducción: en alemán dice "flugbeflissen”: bellísimo neologismo compuesto (para: "con ansia de volar").

9 Nota de traducción: La siguiente traducción de los pasajes de Kafka no es oficial (sino de la autoría de R.B.). El lector o la lectora se encontrará, tal como lo señala el propio Ingold en páginas siguientes, con un texto de ritmo sucesivo e interrumpido, "tosco" en su cadencia imitativa de los atascos mecánicos de un motor y de la conciencia del mecánico que lo repara; aspectos que, en la traducción oficial consultada, más allá de que esta presenta partes demasiado libres, no se veían reflejados.

10 Nota R.B.: En 1912, Reichelt se tira de la Torre Eiffel, convencido de poder aterrizar suavemente. Pierde la vida en este salto, que fue filmado y así se encuentra archivado en Youtube y otros sitios.

11 Traducción R.B.

12 Acerca de la tradición icaria y su continuación cf. Reay (1977).

13 Nota R.B.: Latham sin embargo no muere en un accidente aéreo.

14 Traducción R.B. 